\title{
Atmospheric sulphuric acid and aerosol formation: implications from atmospheric measurements for nucleation and early growth mechanisms
}

\author{
S.-L. Sihto ${ }^{1}$, M. Kulmala ${ }^{1}$, V.-M. Kerminen ${ }^{2}$, M. Dal Maso ${ }^{1}$, T. Petäjä ${ }^{1}$, I. Riipinen ${ }^{1}$, H. Korhonen ${ }^{2}$, F. Arnold ${ }^{3}$, \\ R. Janson ${ }^{4}$, M. Boy ${ }^{1}$, A. Laaksonen ${ }^{5}$, and K. E. J. Lehtinen ${ }^{6}$ \\ ${ }^{1}$ University of Helsinki, Department of Physical Sciences, P.O. Box 64, 00014 University of Helsinki, Finland \\ ${ }^{2}$ Finnish Meteorological Institute, Climate and Global Change, Erik Palmenin Aukio 1, P.O. Box 503, 00101 Helsinki, \\ Finland \\ ${ }^{3}$ Atmospheric Physics Division, Max-Planck Institute for Nuclear Physics (MPIK), P.O. Box 103980, 69029 Heidelberg, \\ Germany \\ ${ }^{4}$ University of Stockholm, Department of Applied Environmental Science, Air Pollution Laboratory, Frescativägen 54, 10691 \\ Stockholm, Sweden \\ ${ }^{5}$ University of Kuopio, Department of Applied Physics, P.O. Box 1627, 70211 Kuopio, Finland \\ ${ }^{6}$ Finnish Meteorological Institute and University of Kuopio, Department of Applied Physics, P.O. Box 1627, 70211 Kuopio, \\ Finland
}

Received: 25 January 2006 - Published in Atmos. Chem. Phys. Discuss.: 15 May 2006

Revised: 28 August 2006 - Accepted: 1 September 2006 - Published: 11 September 2006

\begin{abstract}
We have investigated the formation and early growth of atmospheric secondary aerosol particles building on atmospheric measurements. The measurements were part of the QUEST 2 campaign which took place in spring 2003 in Hyytiälä (Finland). During the campaign numerous aerosol particle formation events occurred of which 15 were accompanied by gaseous sulphuric acid measurements. Our detailed analysis of these 15 events is focussed on nucleation and early growth (to a diameter of $3 \mathrm{~nm}$ ) of fresh particles. It revealed that new particle formation seems to be a function of the gaseous sulphuric acid concentration to the power from one to two when the time delay between the sulphuric acid and particle number concentration is taken into account. From the time delay the growth rates of freshly nucleated particles from $1 \mathrm{~nm}$ to $3 \mathrm{~nm}$ were determined. The mean growth rate was $1.2 \mathrm{~nm} / \mathrm{h}$ and it was clearly correlated with the gaseous sulphuric acid concentration. We tested two nucleation mechanisms - recently proposed cluster activation and kinetic type nucleation - as possible candidates to explain the observed dependences, and determined experimental nucleation coefficients. We found that some events are dominated by the activation mechanism and some by the kinetic mechanism. Inferred coefficients for the two nucleation mechanisms are the same order of magnitude as chemical re-
\end{abstract}

Correspondence to: S.-L. Sihto

(sanna-liisa.sihto@helsinki.fi) action coefficients in the gas phase and they correlate with the product of gaseous sulphuric acid and ammonia concentrations. This indicates that besides gaseous sulphuric acid also ammonia has a role in nucleation.

\section{Introduction}

Atmospheric aerosol particles affect the quality of our life in many different ways. In polluted urban environments, aerosols influence human health and deteriorate visibility (e.g. Donaldson et al., 1998; Stieb et al., 2002; Cabada et al., 2004). In regional and global scales, aerosol particles have a potential to change climate patterns and hydrological cycle (Ramanathan et al., 2001; Sekiguchi et al., 2003; Lohmann and Feichter, 2005). Better understanding of the various effects of atmospheric aerosols requires detailed information on how different sources and transformation processes modify the aerosol properties. An important phenomenon in this regard is atmospheric aerosol formation, which involves the production of nanometre-size particles by nucleation and their growth to detectable sizes (Kulmala, 2003).

Atmospheric aerosol formation followed by growth upto the 50-200 nm size range has been observed commonly in the continental boundary layer. Such observations cover the boreal forest region (Mäkelä et al., 1997; Kulmala et al.,

Published by Copernicus GmbH on behalf of the European Geosciences Union. 
1998, 2001a; Vehkamäki et al., 2004), remote continental sites (Weber et al., 1997; Birmili et al., 2003), industrialised agricultural regions (Birmili and Wiedensohler, 1998), urban and suburban areas (Väkevä et al., 2000; Stanier et al., 2004; Stolzenburg et al., 2005), and heavily-polluted environments (Dunn et al., 2004; Wehner et al., 2004; Laaksonen et al., 2005; Mönkkönen et al., 2005). Aerosol formation has also been observed in coastal environments around Europe (O'Dowd et al., 1999). A recent overview has summarised the formation and growth properties in a global point of view (Kulmala et al., 2004a), quantifying especially the formation and growth rates of nucleation events, where available.

Sulphuric acid is a key component in atmospheric aerosol formation. Several nucleation mechanisms, including binary, ternary and ion-induced nucleation, are likely to involve sulphuric acid (e.g. Bernd et al., 2005; Korhonen et al., 1999; Kulmala, 2003; Kulmala et al., 2004a; Laakso et al., 2004a). A close connection of sulphuric acid and particle formation has been reported by Weber et al. (1995, 1997), whose measurements at two different sites referred to sulphuric acid as a primary precursor species of the ultrafine particles. Some, if not the major, fraction of the particle growth can be explained by sulphuric acid condensation, especially in the smallest particle sizes (Kulmala et al., 2004b; Zhang et al., 2004; Boy et al., 2005; Fiedler et al., 2005; Smith et al., 2005). Sulphuric acid might also play a role in the so-called activation process, in which stable clusters containing one sulphuric acid molecule will be activated for growth (Kulmala et al., 2006). It is therefore important to measure sulphuric acid concentrations and aerosol relevant parameters at the same time in order to quantify the contribution of sulphuric acid to both particle formation and growth.

The present study was inspired by the observation that on new particle formation days, the temporal evolution of the number concentration of nucleation mode particles seems to follow the concentration of sulphuric acid. In view of this, we reanalysed the data from the measurement campaign QUEST 2. The main goal of the QUEST-project (Quantification of Aerosol Nucleation in the European Boundary Layer) has been the qualitative and quantitative analysis of particle nucleation and growth in three European regions. During the QUEST 2 campaign in Hyytiälä (17 March to 13 April 2003), sulphuric acid concentrations and particle number size distributions were measured continuously on 23 days. From these data various quantities, such as the formation and growth rate of aerosol particles, were calculated.

The general goal of this study is to get information about the aerosol formation processes below $3 \mathrm{~nm}$ diameter, which is the lower limit of current instruments for measuring neutral atmospheric particles. More specifically, we aim to address the following questions: i) how sulphuric acid and nucleation mode particle concentrations are related to each other, ii) how large is the particle growth rate from 1 to $3 \mathrm{~nm}$ and what is the reason for its variability, iii) which particle formation mechanism explains the measurement data best, and iv) how large are relevant activation/kinetic constants associated with the different particle formation mechanisms and how the values of these constants vary as a function of measured parameters? The investigation is based on analysis of observed data. The particle growth rate from 1 to $3 \mathrm{~nm}$ will be estimated from the observed time shift between increasing sulphuric acid and ultrafine particle number concentration. Two different particle formation mechanisms will be tested, the recently-developed activation theory (Kulmala et al., 2006) and kinetic (barrierless) nucleation theory (McMurry and Friedlander, 1979; Lushnikov and Kulmala, 1998).

\section{Materials and methods}

\subsection{Measurements}

We utilized the data set of QUEST 2 (Quantification of Aerosol Nucleation in the European Boundary Layer) campaign that was held at the SMEAR II station in Hyytiälä, Finland, in March-April 2003. The QUEST 2 data set is quite unique in the sense that during the campaign a large number of events was observed: of the total of 23 measurement days (from 18 March to 9 April 2003) 20 were new particle formation days. During QUEST 2 campaign a large number of different quantities were measured; here we describe only the measurements relevant to this study.

The measurement station SMEAR II (Station for Measuring Forest Ecosystem - Atmosphere Relations) is located in Southern Finland $\left(61^{\circ} 51^{\prime} \mathrm{N}, 24^{\circ} 17^{\prime} \mathrm{E}, 181 \mathrm{~m}\right.$ a.s.1.) in a rural region with large areas of forested land. The conditions at the station are most of the time relatively clean, even though polluted continental air arrives occasionally from the southeast to south-west directions. Also the nearest city, Tampere, located $60 \mathrm{~km}$ south-west from the station, can influence the local air quality. More information about the station and the measurement equipment can be found in Hari and Kulmala (2005) and at http://www.atm.helsinki.fi/SMEAR/.

Number size distributions of atmospheric aerosol particles from 3 to $500 \mathrm{~nm}$ were measured continuously, with 10-min time resolution, by a DMPS (Differential Mobility Particle Sizer) setup. The setup consists of two parallel differential mobility analyzers (DMAs) that classify particles in size ranges $3-10 \mathrm{~nm}$ and $10-500 \mathrm{~nm}$, the total number of size classes being 32 . The DMPS setup is described in more detail in e.g. Laakso et al. (2004a).

The sulphuric acid concentration was measured by a chemical ionization mass spectrometer (CIMS) built by the MPI-K Heidelberg (see Hanke et al., 2002). The time resolution of the spectrometer was less than $1 \mathrm{~s}$, but the data was averaged over $60 \mathrm{~s}$ in order to reduce statistical error. The sulphuric acid detection limit was $1 \times 10^{5} \mathrm{~cm}^{-3}$ and the relative measurement error $30 \%$.

Temperature, relative humidity and concentrations of trace gases $\left(\mathrm{O}_{3}, \mathrm{NO}_{\mathrm{x}}, \mathrm{SO}_{2}\right)$ are measured continuously at 
SMEAR II station (see Kulmala et al., 2001a). Ammonia and monoterpene concentrations were measured during the campaign as described by Janson et al. (2001), and OH concentrations were estimated using the method described by Boy et al. (2005).

Particle formation events are observed at SMEAR II station on 60-120 days in a year, with maxima in event frequency in spring and autumn (Dal Maso et al., 2005). The particle formation process is expected to be a large scale phenomenon that extends over several hundreds of kilometers (see e.g. Vana et al., 2004). If meteorological conditions remain sufficiently steady during the day, we can assume that particles advected to the station belong to the same large scale nucleation event. Most events are observed on clear, sunny days when this condition is fulfilled. One evidence of the validity of this assumption is the quality of the particle formation event: a clear event with steady growth implies steady meteorological conditions while change in air mass would result in rapid changes in concentrations.

\subsection{Data analysis}

\subsubsection{Estimation of particle formation rates from the DMPS data}

In this study, we focus on the freshly-nucleated particles and their relation to the sulphuric acid concentration. From the DMPS data we consider the size range 3-6 nm that covers the four lowest DMPS channels. This size range is small enough to be considered as freshly nucleated but still large enough to achieve relatively good statistics and reduce the influence of measurement uncertainties present in the lowest DMPS channels. The particle number concentration in this 3-6 $\mathrm{nm}$ size range is denoted by $N_{3-6}$.

The time evolution of $N_{3-6}$ is described with a balance equation

$$
\frac{d N_{3-6}}{d t}=G R_{3 \mathrm{~nm}} \cdot n_{3 \mathrm{~nm}}-G R_{6 \mathrm{~nm}} \cdot n_{6 \mathrm{~nm}}-\operatorname{CoagS}_{3-6} \cdot N_{3-6},
$$

including terms for growth into the 3-6nm range over the $3 \mathrm{~nm}$ barrier, out of the range over the $6 \mathrm{~nm}$ barrier and loss by coagulation scavenging. Here, $G R$ denotes particle growth rate, and the function $n$ is a particle size distribution function, defined as $n=d N / d d_{p}$ with $d_{p}=$ particle diameter. $\mathrm{CoagS}_{3-6}$ denotes the average coagulation sink for the 3-6 nm range (Kulmala et al., 2001b). By rearranging the terms, and denoting the first term on the right hand side of Eq. (1) by $J_{3}$, the following equation is obtained:

$J_{3}=\frac{d N_{3-6}}{d t}+\operatorname{CoagS}_{d_{p}=4 \mathrm{~nm}} \cdot N_{3-6}+\frac{1}{3 \mathrm{~nm}} G R \cdot N_{3-6}$.

$J_{3}$ is the apparent nucleation rate, i.e. the formation rate of new particles into the measurable range of above $3 \mathrm{~nm}$. Here the coagulation loss (last term on the right hand side of Eq. 1) for the interval 3-6nm has been approximated by a term representing loss of $4 \mathrm{~nm}$ sized particles ( $4 \mathrm{~nm}$ is approximately the geometric mean of 3 and $6 \mathrm{~nm}$ ) with concentration $N_{3-6}$. The coagulation sink $\operatorname{CoagS}_{d_{p}=4 \mathrm{~nm}}$ is directly calculated from the measured background particle size distribution, with hygroscopicity effects estimated as in Laakso et al. (2004b). The third term representing loss due to condensation out of the 3-6 $\mathrm{nm}$ size range comes from approximating $n_{6 \mathrm{~nm}}$ and $G R_{6 \mathrm{~nm}}$ by $N_{3-6} /(6 \mathrm{~nm}-3 \mathrm{~nm})$ and $G R$, respectively. Here $G R$ is estimated from the time delay between sulphuric acid and $N_{3-6}$ as explained in Sect. 2.2.2. The first term on the right hand side of Eq. (2), the change in the 3$6 \mathrm{~nm}$ particle number concentration, is directly obtained from the DMPS measurement data.

The magnitude of the coagulation loss term relative to the term $d N_{3-6} / d t$ in Eq. (2) depends strongly on the magnitude of the coagulation sink: with small coagulation sink values it has an effect of the order of $10 \%$ or less, but with large coagulation sink values the correction can be of the same order or greater than the term $d N_{3-6} / d t$. The last term is negligible in the beginning of the event, but at later stages may become of the same order as $d N_{3-6} / d t$.

2.2.2 Time shift analysis: growth rate $G R_{1-3}$ and correlation of $N_{3-6}$ and $\left[\mathrm{H}_{2} \mathrm{SO}_{4}\right]$

There is quite a vast consensus in the scientific community that sulphuric acid is participating in the formation of new particles in some way. This is supported by the observed close connection between concentrations of sulphuric acid and small particles: during nucleation events an increase in the concentration of small particles is often preceded by an increase in sulphuric acid concentration. This time delay $\Delta t$ between the rise in sulphuric acid and particle number concentration can be interpreted as the time it takes for the clusters to grow from the nucleated size of $\sim 1 \mathrm{~nm}$ to the detectable size of $3 \mathrm{~nm}$ in diameter. Based on this assumption the growth rate from $1 \mathrm{~nm}$ to $3 \mathrm{~nm}$ can be estimated as:

$G R_{1-3}=\frac{\Delta d_{p}}{\Delta t}=\frac{2 \mathrm{~nm}}{\Delta t}$.

This method to determine growth rate of freshly nucleated particles may be termed "time-shift analysis" and it has been used previously by Fiedler et al. (2005) in connection with the QUEST 2 campaign. Here we extend this concept in such a way that also the correlation of number concentration of small 3-6 nm particles $\left(N_{3-6}\right)$ and sulphuric acid $\left(\left[\mathrm{H}_{2} \mathrm{SO}_{4}\right]\right)$ is investigated so that the time delay between them is taken into account.

In this study, it was noticed soon that there exist two types of correlations between $N_{3-6}$ and $\mathrm{H}_{2} \mathrm{SO}_{4}$ concentration: on some days $N_{3-6}$ follows the shape of $\left[\mathrm{H}_{2} \mathrm{SO}_{4}\right]$ curve while on other days $N_{3-6}$ correlates clearly with $\left[\mathrm{H}_{2} \mathrm{SO}_{4}\right]^{2}$. Therefore, on some days the time delay $\Delta t$ was taken between the $N_{3-6}$ and $\left[\mathrm{H}_{2} \mathrm{SO}_{4}\right]$ curves and on other days between the $N_{3-6}$ and $\left[\mathrm{H}_{2} \mathrm{SO}_{4}\right]^{2}$ curves. Regardless of the prevailing 
relationship between $N_{3-6}$ and $\left[\mathrm{H}_{2} \mathrm{SO}_{4}\right]$, the interpretation of $\Delta t$ as the growth time from $\sim 1 \mathrm{~nm}$ to $3 \mathrm{~nm}$ stays the same.

The investigation of the relationship between particle concentration $N_{3-6}$ and sulphuric acid was started by determining the time lag (delay) between the increases in concentrations $N_{3-6}$ and $\left[\mathrm{H}_{2} \mathrm{SO}_{4}\right]$. When this time lag was taken into account by delaying the $\left[\mathrm{H}_{2} \mathrm{SO}_{4}\right]$ curve by $\Delta t$, the correlation of $N_{3-6}$ and $\left[\mathrm{H}_{2} \mathrm{SO}_{4}\right]$ became very clear. The correlation was examined both by visually investigating the $N_{3-6}$ and $\left[\mathrm{H}_{2} \mathrm{SO}_{4}\right]$ curves and by calculating correlation coefficients for $N_{3-6}$ and $\left[\mathrm{H}_{2} \mathrm{SO}_{4}\right]$ or $\left[\mathrm{H}_{2} \mathrm{SO}_{4}\right]^{2}$. The time delays were determined independently for the two dependences $\left(N_{3-6} \sim\left[\mathrm{H}_{2} \mathrm{SO}_{4}\right]\right.$ and $\left.N_{3-6} \sim\left[\mathrm{H}_{2} \mathrm{SO}_{4}\right]^{2}\right)$ and correlation coefficients were calculated for the both cases with appropriate time delays. All event days were classified according to which type of correlation - with $\left[\mathrm{H}_{2} \mathrm{SO}_{4}\right]$ to the power of 1 or 2 - was prevailing.

There is a close interplay between the determination of the time delay $\Delta t$ and the type of correlation of $N_{3-6}$ and $\left[\mathrm{H}_{2} \mathrm{SO}_{4}\right]$. If the time delay is taken between $N_{3-6}$ and $\left[\mathrm{H}_{2} \mathrm{SO}_{4}\right]$ curves we get typically a different value than if the time delay is taken between $N_{3-6}$ and $\left[\mathrm{H}_{2} \mathrm{SO}_{4}\right]^{2}$. Furthermore, we may get different values for $\Delta t$ if we consider only the first rise of the curves or look at the time lag between the whole curves. For these reasons, there may be subjectivity or at least some variation in the determination of the time lag between different persons, especially on days when there are some interfering processes present e.g. due to changing air mass.

Generally the time delay is most evident in the rising part of the curve, and therefore in most cases that part was given the greatest weight. Also similar peaks in $N_{3-6}$ and $\left[\mathrm{H}_{2} \mathrm{SO}_{4}\right]$ during later stages of the event were used in some cases. However, on some days, the form of the whole curve was used to determine the time delay, because that gave overall better agreement between the curves. In general, the time delay was determined by looking the $N_{3-6}$ and $\left[\mathrm{H}_{2} \mathrm{SO}_{4}\right]$ curves as a whole and not restricting to the rising part only.

\subsubsection{Atmospheric nucleation rates}

If the formation rate of $3 \mathrm{~nm}$ particles $J_{3}$ is known, the nucleation rate $J_{1}$ at time $t=t^{\prime}-\Delta t$ can be estimated using the method presented by Kerminen and Kulmala (2002):

$J_{1}(t)=J_{3}\left(t^{\prime}\right) \exp \left(\gamma \frac{C S^{\prime}}{G R}\left(\frac{1}{1 \mathrm{~nm}}-\frac{1}{3 \mathrm{~nm}}\right)\right)$.

Here $C S^{\prime}$ is the condensation sink (in units $\mathrm{m}^{-2}$ ), $G R$ is the growth rate (in $\mathrm{nm} / \mathrm{h}$ ) and $\gamma$ is a coefficient with a value of about $0.23 \mathrm{~m}^{2} \mathrm{~nm}^{2} \mathrm{~h}^{-1}$.

Thus we first estimate the formation rate of $3 \mathrm{~nm}$ partices $\left(J_{3}\right)$ from the DMPS measurement data using Eq. (2) and then the nucleation rate of $\sim 1 \mathrm{~nm}$ particles $J_{1}(t)$ from Eq. (4). For the condensation sink $C S^{\prime}$ we use the median value from the interval $[t, t+\Delta t]$.
A correlation between $N_{3-6}$ and $\left[\mathrm{H}_{2} \mathrm{SO}_{4}\right]$ or $\left[\mathrm{H}_{2} \mathrm{SO}_{4}\right]^{2}$ suggests that sulphuric acid is participating in nucleation in some way. Using $J_{1}$ and $J_{3}$ estimated from the particle measurement data we test two hypothetic nucleation mechanisms that should have a power law dependence on the sulphuric acid concentration.

The first nucleation mechanism to be tested we call "activation type nucleation" and it is directly proportional to the sulphuric acid concentration. This mechanism was recently proposed by Kulmala et al. (2006). Nucleation is thought to happen as activation of small clusters containing one sulphuric acid molecule via e.g. heterogeneous nucleation or heterogeneous chemical reactions. Because critical clusters are assumed to contain one sulphuric acid molecule, nucleation rate is directly proportional to sulphuric acid concentration. We do not make any assumptions of the specific growth mechanism or vapours participating in the cluster activation process, but express the nucleation rate simply by (Kulmala et al., 2006):

$J_{1}=A\left[\mathrm{H}_{2} \mathrm{SO}_{4}\right]$,

where the coefficient $A$ will be determined according to measurement data. This activation coefficient $A$ contains the physics and chemistry of the nucleation process; however, so far it is merely an empirical coefficient. Studying the variation of $A$ and its dependences on different quantities can give us information on details of the nucleation process.

The second nucleation mechanism to be tested has the functional form of kinetic nucleation of molecules containing sulphuric acid, i.e. it is proportional to the square of sulphuric acid concentration. This mechanism we call "kinetic type nucleation". In kinetic nucleation, critical clusters are formed by collisions of sulphuric acid molecules or other molecules containing sulphuric acid, e.g. ammonium bisulphate molecules. The upper limit for kinetic nucleation, so called "kinetic limit", is set by the collision rate of molecules given by the kinetic theory of gases. Here we let the collision frequency function be a free parameter and calculate nucleation rate as:

$J_{1}=K\left[\mathrm{H}_{2} \mathrm{SO}_{4}\right]^{2}$,

where the coefficient $K$ will be adjusted to fit $J_{1}$ calculated from particle measurement data. This kinetic coefficient $K$ contains again the details of the nucleation process, specifically the probability that a collision of two sulphuric acid containing molecules results in the formation of a stable critical cluster.

The nucleation coefficients $A$ and $K$ are determined as follows. From the measurement data we get $J_{3}$ using Eq. (2) and from that nucleation rate $J_{1}$ is calculated by using Eq. (4). Then we calculate the nucleation rate $J_{1}$ from the measured sulphuric acid concentration according to the two hypothetic nucleation mechanisms, activation type and kinetic type nucleation (Eqs. 5 and 6). These nucleation rates are further 


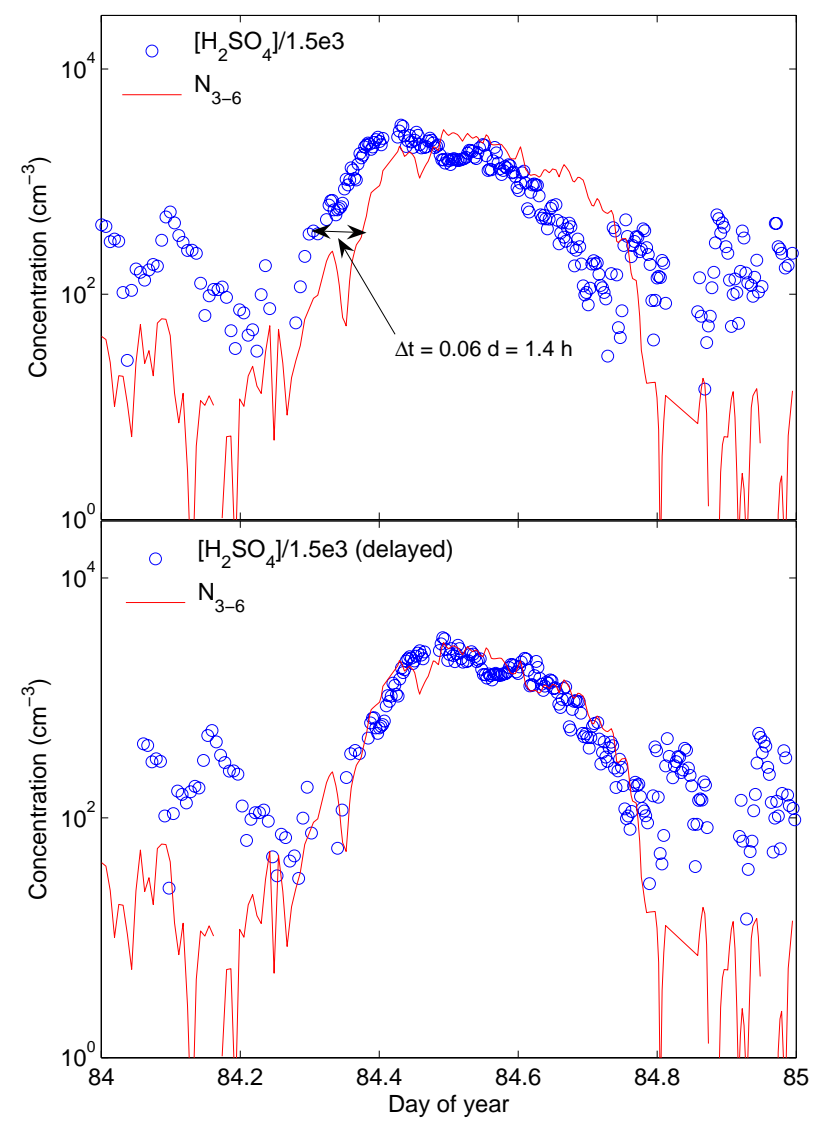

Fig. 1a. (upper panel) Number concentration of 3-6 nm particles $\left(N_{3-6}\right)$ and sulphuric acid concentration (scaled) for day $84(25$ March 2003). The time shift $\Delta t$ between the curves is marked by an arrow. (lower panel) $N_{3-6}$ and $\left[\mathrm{H}_{2} \mathrm{SO}_{4}\right]$ delayed by the time shift $\Delta t=1.4 \mathrm{~h}$, showing excellent correspondence between $N_{3-6}$ and $\left[\mathrm{H}_{2} \mathrm{SO}_{4}\right]$ during the event.

scaled to formation rates of $3 \mathrm{~nm}$ particles using Eq. (4) in the opposite direction than above. Now we have two quantities to compare: $J_{1}$ estimated from the particle concentrations and $J_{1}$ calculated from the sulphuric acid concentration, and similarly, $J_{3}$ calculated from the particle concentrations and $J_{3}$ estimated from the nucleation rates calculated from the sulphuric acid concentration. By comparing the $J_{1}$ curves with each other we search for the values for the coefficients $A$ and $K$ that give the best agreement with the $J_{1}$ estimated from particle measurements. In the same way we compare the $J_{3}$ curves, to double-check the values of $A$ and $K$. The comparison of $J_{1}$ and $J_{3}$ curves is done only visually, because in that way the essential features can be simply picked up to be taken into account, and some interfering peaks in the data due to e.g. changing air mass can be left out from the analysis. Computational fitting methods, such as calculation of correlation coefficients, would not work here well because of quite big variations present in the $J_{1}$ and $J_{3}$ data. Furthermore, in the first place we want to get an order of magnitude

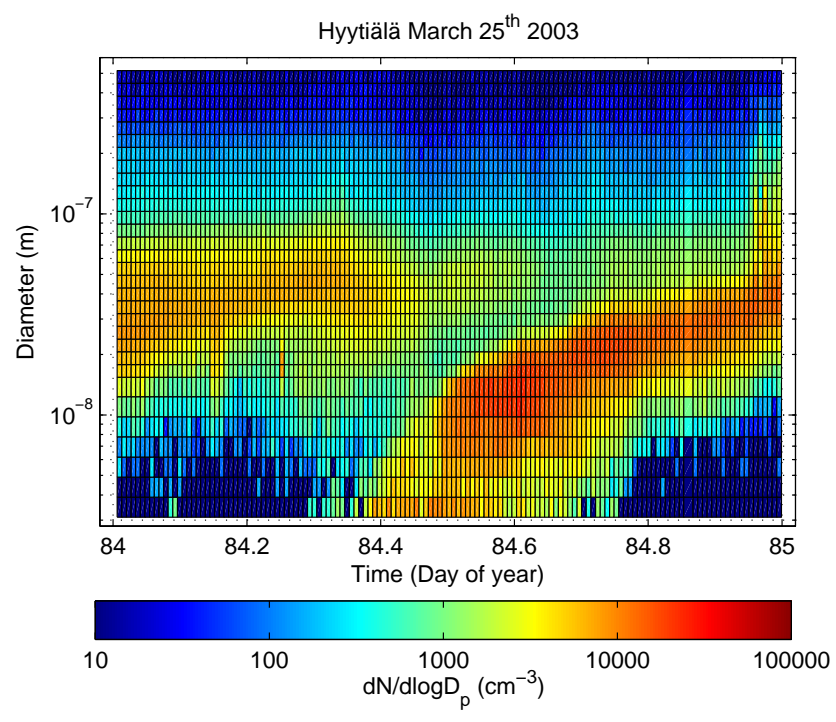

Fig. 1b. Surface plot showing the time evolution of particle size distribution on day 84 (25 March 2003) measured by DMPS. Time is on the $\mathrm{x}$-axis, particle diameter on the $\mathrm{y}$-axis and colour indicates normalized number concentration.

information about the nucleation coefficients and the exact numerical values are not crucial, so the use of computational fitting methods would be dispensable.

\section{Results and discussion}

During QUEST 2 campaign new particle formation was observed to occur on 20 days of the total of 23 measurement days. For some event days sulphuric acid data was missing, and for this analysis we had the data on 15 particle formation days.

\subsection{Correlation of $N_{3-6}$ and sulphuric acid}

On all 15 days that were analysed the number concentration in size range 3-6 $\mathrm{nm}\left(N_{3-6}\right)$ and sulphuric acid concentration were clearly correlated. On some days $N_{3-6}$ correlated with $\left[\mathrm{H}_{2} \mathrm{SO}_{4}\right]$ but on other days the $N_{3-6}$ curve had a similar shape as the $\left[\mathrm{H}_{2} \mathrm{SO}_{4}\right]^{2}$ curve. Figure 1a presents an example of direct correlation between $N_{3-6}$ and $\left[\mathrm{H}_{2} \mathrm{SO}_{4}\right]$ observed on day 84 (25 March 2003); the surface plot for the event is shown in Fig. 1b. From Fig. 1a it is clearly seen, that the forms of the $N_{3-6}$ and $\left[\mathrm{H}_{2} \mathrm{SO}_{4}\right]$ curves are almost identical during the particle formation event that spans approximately from 07:00 a.m. to 07:00 p.m. (84.3-84.8 in days). However, there is a time lag between the curves arising from the time required for the nucleated clusters to grow to the size of $3 \mathrm{~nm}$ detectable by DMPS. In the lower panel of Fig. 1a the $\left[\mathrm{H}_{2} \mathrm{SO}_{4}\right]$ curve has been delayed by the time shift $\Delta t=1.4 \mathrm{~h}$, and in this figure the direct correlation between $N_{3-6}$ and $\left[\mathrm{H}_{2} \mathrm{SO}_{4}\right]$ is even more evident. 


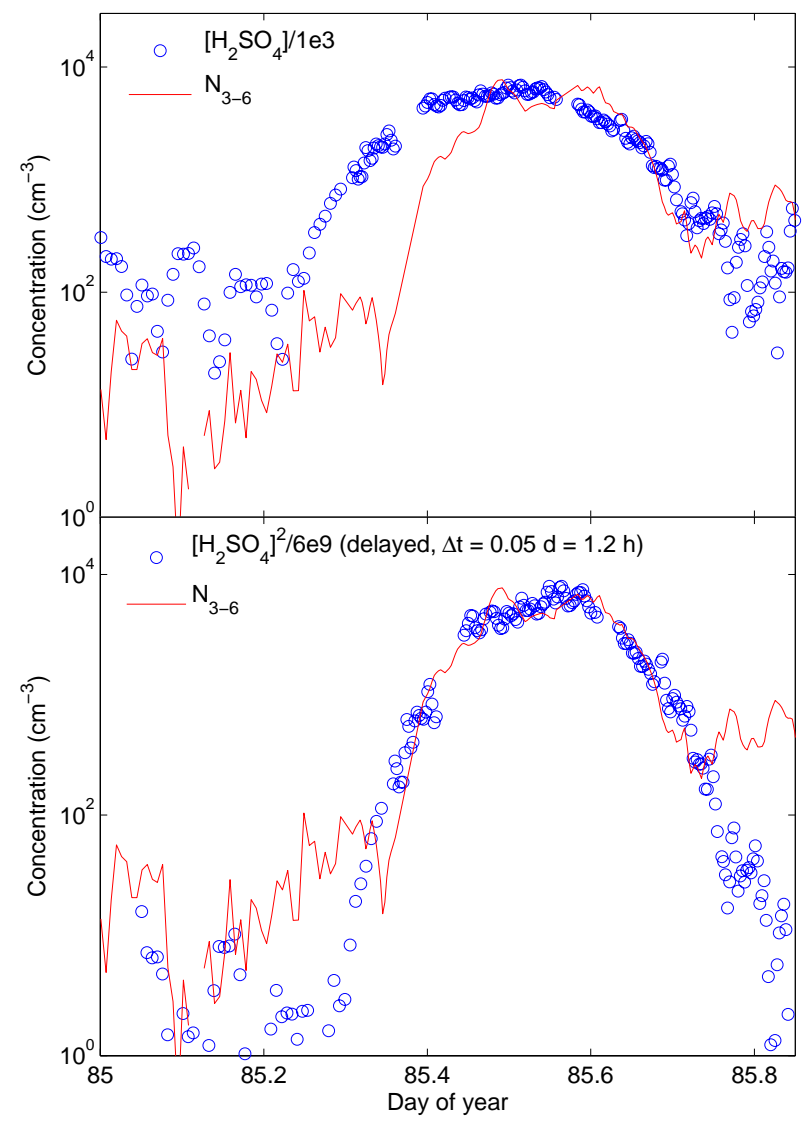

Fig. 2a. (upper panel) Number concentration of 3-6 $\mathrm{nm}$ particles $\left(N_{3-6}\right)$ and sulphuric acid concentration (scaled) for day 85 (26 March 2003). (lower panel) $N_{3-6}$ and $\left[\mathrm{H}_{2} \mathrm{SO}_{4}\right]^{2}$ (scaled) delayed by the time shift $\Delta t=1.2 \mathrm{~h}$, showing clear correlation between $N_{3-6}$ and $\left[\mathrm{H}_{2} \mathrm{SO}_{4}\right]^{2}$ during the event.

Figures $2 \mathrm{a}$ and $2 \mathrm{~b}$ present an example of a day when $N_{3-6}$ correlates with the square of $\left[\mathrm{H}_{2} \mathrm{SO}_{4}\right]$. The upper panel of the Fig. 2a shows that $N_{3-6}$ and $\left[\mathrm{H}_{2} \mathrm{SO}_{4}\right]$ are somewhat related to each other, but they are not directly correlated even if the time lag between the curves was taken into account. However, when we plot the square of $\left[\mathrm{H}_{2} \mathrm{SO}_{4}\right]$ and delay it by $\Delta t=1.2 \mathrm{~h}$, it coincides well with the $N_{3-6}$ curve. It is worth noting that the correlation between $N_{3-6}$ and $\left[\mathrm{H}_{2} \mathrm{SO}_{4}\right]$ or $N_{3-6}$ and $\left[\mathrm{H}_{2} \mathrm{SO}_{4}\right]^{2}$ stays the same during the whole nucleation event, not only at the start of the event when the time lag is visible. This suggests that the growth rate from 1 to $3 \mathrm{~nm}$ is relatively constant the whole day.

The time delays and types of correlation $-N_{3-6} \sim\left[\mathrm{H}_{2} \mathrm{SO}_{4}\right]$ or $N_{3-6} \sim\left[\mathrm{H}_{2} \mathrm{SO}_{4}\right]^{2}-$ were determined for all 15 days. From the time delay $\Delta t$ the growth rate from nucleated size of $\sim 1 \mathrm{~nm}$ to detectable size of $3 \mathrm{~nm}, G R_{1-3}$, was calculated by Eq. (3). The results are collected in Table 1. The time delay varied between 1.0 and $4.1 \mathrm{~h}$ with a mean value of $2.0 \mathrm{~h}$, median of $1.7 \mathrm{~h}$ and standard deviation of $0.9 \mathrm{~h}$. After omitting the two largest values on days 90 and 93 , standard devia-

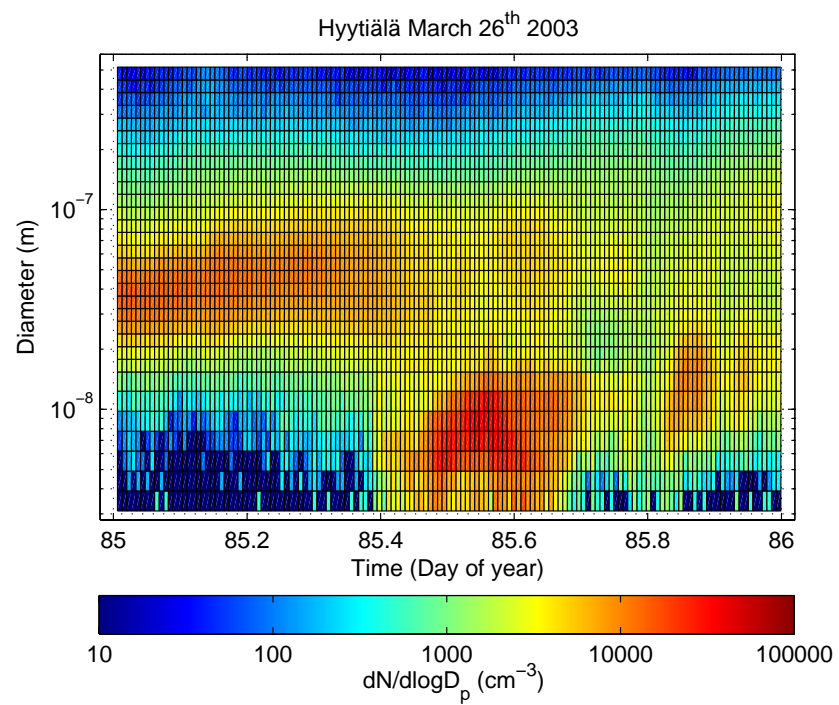

Fig. 2b. Surface plot showing the time evolution of particle size distribution on day 85 (26 March 2003) measured by DMPS. Time is on the $\mathrm{x}$-axis, particle diameter on the $\mathrm{y}$-axis and colour indicates normalized number concentration.

tion of $\Delta t$ was considerably smaller $(0.5 \mathrm{~h})$ and mean value changed to $1.7 \mathrm{~h}$ while median stayed the same. The growth rates corresponding to these time delays were in the range $0.5-2.1 \mathrm{~nm} / \mathrm{h}$ with mean and median of $1.2 \mathrm{~nm} / \mathrm{h}$ and standard deviation of $0.5 \mathrm{~nm} / \mathrm{h}$. The reason for the same mean and median values of $G R_{1-3}$, as opposed to the different mean and median of $\Delta t$, is that in the $G R_{1-3}$ formula (Eq. 3) $\Delta t$ is in the denominator. In case of $G R_{1-3}$, omitting the days 90 and 93 from the data set had only a minor influence to mean, median and standard deviation, which again was due to the fact that $\Delta t$ is in the denominator.

The fraction of the growth rate $G R_{1-3}$ that could be explained by the condensation of sulphuric acid can be estimated by comparing $G R_{1-3}$ to the growth rate calculated from the sulphuric acid concentration. This latter can be calculated from (Kulmala et al., 2001b):

$G R=\frac{d d_{p}}{d t}=\frac{4 \beta_{M} M_{\mathrm{H}_{2} \mathrm{SO}_{4}} D_{\mathrm{H}_{2} \mathrm{SO}_{4}} C_{\mathrm{H}_{2} \mathrm{SO}_{4}}}{\rho d_{p}}$,

where $M_{\mathrm{H} 2 \mathrm{SO} 4}$ is the molecular mass of sulphuric acid, $D_{\mathrm{H} 2 \mathrm{SO}} 4$ is its diffusion coefficient, $C_{\mathrm{H} 2 \mathrm{SO} 4}$ is its concentration, $\rho$ is the particle density and $\beta_{M}$ is the Fuchs-Sutugin transitional correction factor. This equation is derived for spherical nucleation mode particles from macroscopic condensation theory, and these assumptions do not hold anymore for 1-3 nm sized particles. Lehtinen and Kulmala (2003) have considered condensation with a molecular resolution and found that condensation is enhanced at small particle sizes compared with the macroscopic treatment. According to calculations made with an aerosol dynamic model UHMA (Korhonen et al., 2004), the condensation rate is enhanced by 
Table 1. Time delay $(\Delta t)$ between $N_{3-6}$ and $\left[\mathrm{H}_{2} \mathrm{SO}_{4}\right]$ or $\left[\mathrm{H}_{2} \mathrm{SO}_{4}\right]^{2}$ and the corresponding growth rate from $1 \mathrm{~nm}$ to $3 \mathrm{~nm}\left(G R_{1-3}\right)$ for 15 event days during QUEST 2 campaign in Hyytiälä, Finland. The fourth column indicates which correlation was better, and the last two columns the correlation coefficients (R) for correlations $N_{3-6} \sim\left[\mathrm{H}_{2} \mathrm{SO}_{4}\right]^{1}$ or 2 with $\left[\mathrm{H}_{2} \mathrm{SO}_{4}\right]$ delayed by $\Delta t$. A minus sign indicates that the quantity could not be determined.

\begin{tabular}{cccccc}
\hline Day & $\begin{array}{c}\Delta \mathrm{t} \\
(\mathrm{h})\end{array}$ & $\begin{array}{c}\mathrm{GR}_{1-3} \\
(\mathrm{~nm} / \mathrm{h})\end{array}$ & $\begin{array}{c}\text { Exponent of } \\
\text { the correlation }\end{array}$ & $\begin{array}{c}\mathrm{R} \\
\text { exp. 1 }\end{array}$ & $\begin{array}{c}\mathrm{R} \\
\text { exp. 2 }\end{array}$ \\
\hline 78 & 2.4 & 0.8 & - & 0.57 & 0.55 \\
79 & 1.9 & 1.0 & 2 & 0.70 & 0.82 \\
80 & 2.2 & 0.9 & 2 & $0.90^{*}$ & $0.92^{*}$ \\
82 & 1.7 & 1.2 & 2 & 0.83 & 0.84 \\
84 & 1.4 & 1.4 & 1 & 0.92 & 0.85 \\
85 & 1.2 & 1.7 & 2 & 0.90 & 0.93 \\
87 & 2.4 & 0.8 & 1 & 0.85 & 0.78 \\
88 & - & - & - & - & - \\
90 & 3.6 & 0.6 & 1 & 0.87 & 0.80 \\
91 & 1.2 & 1.7 & 2 & 0.91 & 0.93 \\
92 & 1.2 & 1.7 & - & $0.77^{*}$ & $0.77^{*}$ \\
93 & 4.1 & 0.5 & 2 & $0.95^{*}$ & $0.93^{*}$ \\
94 & 1.7 & 1.2 & 2 & 0.71 & 0.59 \\
96 & 2.4 & 0.8 & 1 & $0.81^{*}$ & $0.69^{*}$ \\
97 & 1.0 & 2.1 & 1 & 0.79 & 0.66 \\
98 & 1.2 & 1.7 & 2 & $0.93^{*}$ & $0.92^{*}$ \\
\hline Mean & 2.0 & 1.2 & & & \\
Median & 1.7 & 1.2 & & & \\
Std deviation & 0.9 & 0.5 & & & \\
\hline & & & & &
\end{tabular}

* In the calculation of the correlation coefficient only a period of the day is considered during which the correlation is observable.

a factor between 2 and 3 compared with the value obtained by Eq. (7) for 1-3 nm particles. According to Eq. (7) with a condensation enhancement factor of 2.5, sulphuric acid can explain on average about $50 \%$ of the growth rate from 1 to $3 \mathrm{~nm}$, but on three days even over $70 \%$ (see Fig. 3). As seen from Fig. 3, the contribution of sulphuric acid to the particle growth increases, on average, with increasing sulphuric acid concentration. Exact numbers about the contribution of sulphuric acid cannot be given, but these estimations reveal that on some days sulphuric acid may be responsible for the main part of particle growth from 1 to $3 \mathrm{~nm}$. However, sulphuric acid alone cannot explain the growth on all days.

The relation between $N_{3-6}$ and $\left[\mathrm{H}_{2} \mathrm{SO}_{4}\right]$ followed the pattern $N_{3-6} \sim\left[\mathrm{H}_{2} \mathrm{SO}_{4}\right]$ on six days and pattern $N_{3-6} \sim\left[\mathrm{H}_{2} \mathrm{SO}_{4}\right]^{2}$ on five days (see Table 1 ). The judgement on the type of the correlation was based on both visual perception and correlation coefficients. The difference in correlation coefficients $\mathrm{R}$ is in many cases so small that only based on it, it would be impossible to say which correlation is the better one. However, by looking the data visually, in most cases it was quite clear which correlation was better. By visually looking at the curves we can easily exclude from the

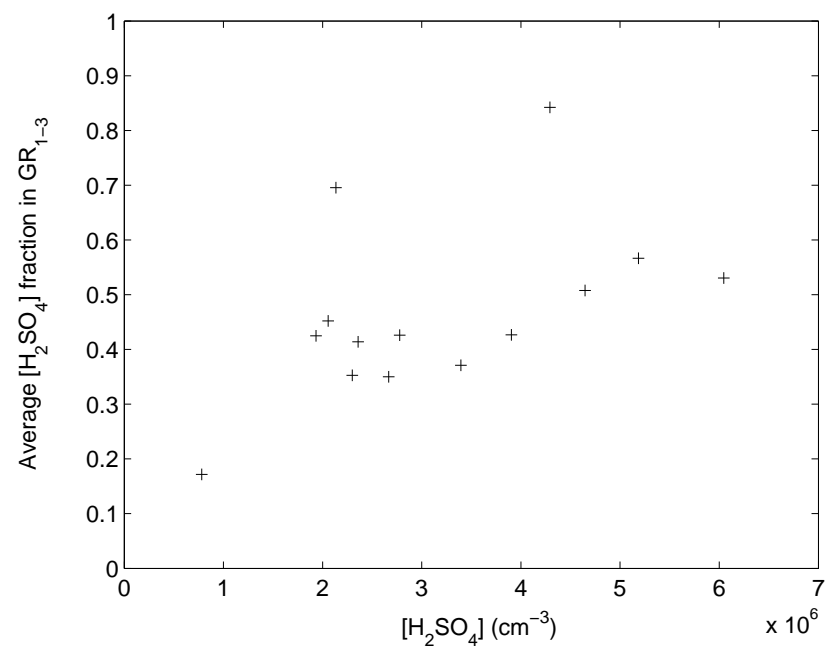

Fig. 3. Average contribution of sulphuric acid to growth from $1 \mathrm{~nm}$ to $3 \mathrm{~nm}$ as a function of mean sulphuric acid concentration on event days during QUEST 2 campaign. One point represents average on one day from 09:00 a.m. to 03:00 p.m. A point at $\left[\mathrm{H}_{2} \mathrm{SO}_{4}\right]=9 \times 10^{6} \mathrm{~cm}^{-3}$ for which $\left[\mathrm{H}_{2} \mathrm{SO}_{4}\right]$ can explain the growth completely is not indicated in the figure.

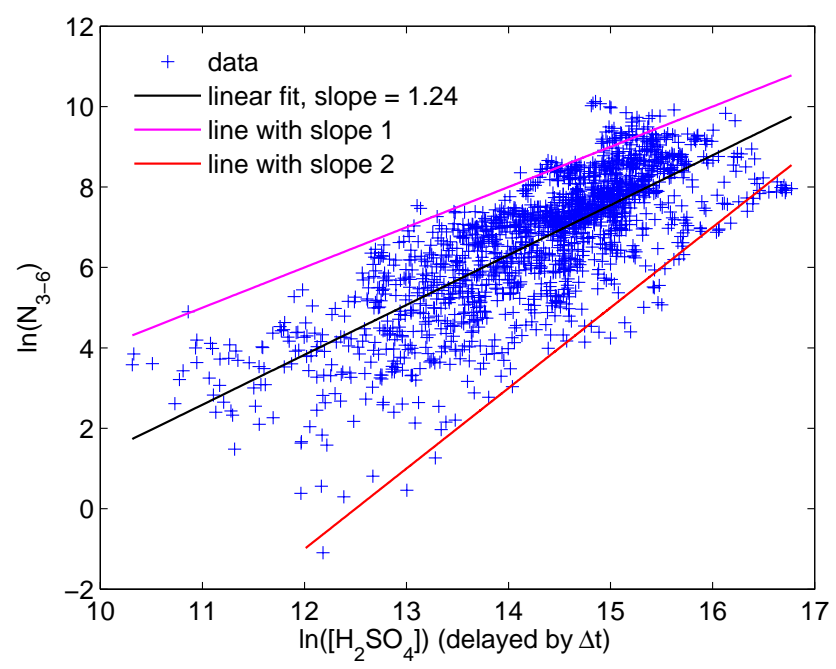

Fig. 4. Logarithm of the number concentration of 3-6 nm particles $\left(N_{3}-6\right)$ versus logarithm of the sulphuric acid concentration during particle formation events. The time shift between $N_{3-6}$ and $\left[\mathrm{H}_{2} \mathrm{SO}_{4}\right]$ has been taken into account by delaying $\left[\mathrm{H}_{2} \mathrm{SO}_{4}\right]$ by $\Delta t$. Linear fit to the data by the method of least squares and lines corresponding relationships $N_{3-6} \sim\left[\mathrm{H}_{2} \mathrm{SO}_{4}\right]$ and $N_{3-6} \sim\left[\mathrm{H}_{2} \mathrm{SO}_{4}\right]^{2}$ are shown.

analysis e.g. some pollution peaks that are clearly not related to new particle formation, but which would contribute to the correlation coefficient significantly.

For days 78 and 92 no exponent is given, because for those days it was not possible to determine which exponent was better. When calculating the correlation coefficients for the 

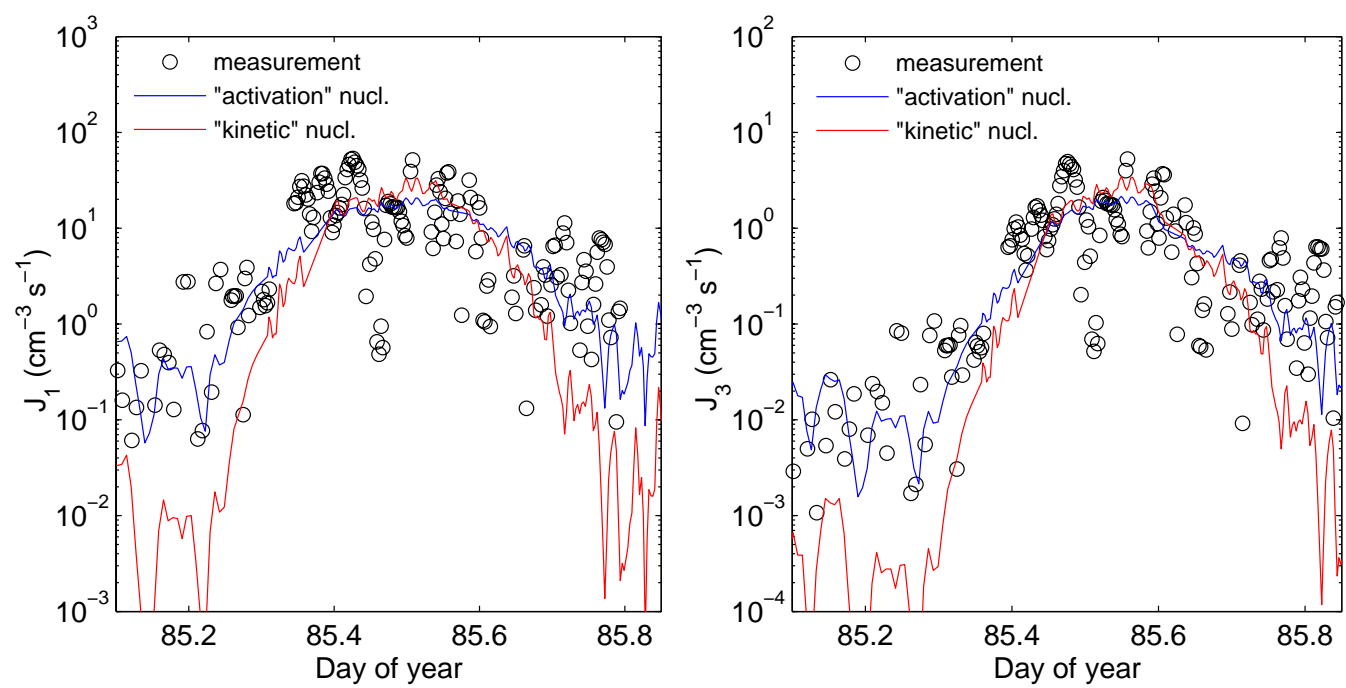

Fig. 5. Nucleation rate $\left(J_{1}\right.$, left panel) and formation rate of $3 \mathrm{~nm}$ particles ( $J_{3}$, right panel) on day 85 (26 March 2003$)$ estimated from the particle measurements and calculated from the sulphuric acid concentration using two hypothetic nucleation mechanisms: "activation type" and "kinetic type" nucleation.

two dependences (with exponent 1 and 2) we used time delays that were determined independently for the two dependences. In most cases we got somewhat different time delays for exponents 1 and 2, and in some cases even significantly different values. In Table 1 only the time delay for the chosen dependence $\left(N_{3-6} \sim\left[\mathrm{H}_{2} \mathrm{SO}_{4}\right]\right.$ or $\left.N_{3-6} \sim\left[\mathrm{H}_{2} \mathrm{SO}_{4}\right]^{2}\right)$ is presented.

On some days there were some interfering peaks in the data that were clearly due to some other phenomenon than the chain "nucleation-growth-observation at 3-6 nm". For those days the correlation coefficient was calculated only for that part of the data where the correlation between $N_{3-6}$ and $\left[\mathrm{H}_{2} \mathrm{SO}_{4}\right]$ was clear; this is indicated by an asterisk in Table 1 . For other days the correlation coefficients were calculated using the whole data. However, also in that case the event period contributes the most to the correlation coefficient because the concentrations are highest during the event. On all days (except day 94) the correlation coefficient for the prevailing correlation $-N_{3-6} \sim\left[\mathrm{H}_{2} \mathrm{SO}_{4}\right]$ or $N_{3-6} \sim\left[\mathrm{H}_{2} \mathrm{SO}_{4}\right]^{2}-$ was greater than 0.79 , and on six days even over 0.9. This demonstrates that the correlation between $N_{3-6}$ and $\left[\mathrm{H}_{2} \mathrm{SO}_{4}\right]$ or $\left[\mathrm{H}_{2} \mathrm{SO}_{4}\right]^{2}$ is remarkably strong on most days.

The overall relation between $N_{3-6}$ and $\left[\mathrm{H}_{2} \mathrm{SO}_{4}\right]$ is shown in Fig. 4, in which the logarithm of $N_{3-6}$ is plotted versus the logarithm of $\left[\mathrm{H}_{2} \mathrm{SO}_{4}\right]$, delayed by $\Delta t$ separately for each day. Here we have included the data during events; the data in early morning and late night is left out because at those times both sulphuric acid concentration and $N_{3-6}$ are low and there is no new particle formation. The chosen time interval varies between the days, but most often it is the period from 06:00 a.m. to 06:00 p.m. In this scatter plot, the slope tells the exponent in the correlation $N_{3-6} \sim\left[\mathrm{H}_{2} \mathrm{SO}_{4}\right]^{x}$. From
Fig. 4 it can be clearly seen that the exponent $x$ lies somewhere between 1 and 2. However, separate cases with the exponent 1 and 2 could not be distinguished from the scatter plot, as was done in the day-by-day comparison of the $N_{3-6}$ and $\left[\mathrm{H}_{2} \mathrm{SO}_{4}\right]$ curves, since in the scatter plot points from different days are mixed together. A least squares fit to the data gives 1.24 for the exponent, representing an average value for the exponent in the entire 15-day data set.

\subsection{Testing different nucleation mechanisms}

The formation rate of $3 \mathrm{~nm}$ particles $\left(J_{3}\right)$ was calculated from particle measurements using Eq. (2) and scaled to the estimated nucleation rate $J_{1}$ using the formula (4). These formation rates are referred to as "measured" henceforth. In order to test the two hypothetic nucleation mechanisms, "activation type" and "kinetic type" nucleation, we calculated the nucleation rate $J_{1}$ from measured sulphuric acid concentration assuming a linear or square dependence on the sulphuric acid concentration. The coefficients $A$ and $K$ in Eqs. (5) and (6) were free parameters that were adjusted to fit the "measured" nucleation rates. Furthermore, we used the formula (4) to convert the "activation type" and "kinetic type" nucleation rates $J_{1}$ into the formation rate $J_{3}$ which then could be compared with the "measured" $J_{3}$ estimated from the DMPS data.

An example of the "measured" nucleation rate compared with the ones calculated from the sulphuric acid concentration according to "activation" and "kinetic" hypotheses is shown in Fig. 5. The values of activation and kinetic coefficients $(A$ and $K$ ) were adjusted so that during nucleation event the agreement was best. For this day (day 85) it seems 
Table 2. Values for nucleation coefficients determined from fittings to experimental data: activation coefficient $A$ in the formula of activation type nucleation, and kinetic coefficient $K$ in the formula of kinetic nucleation.

\begin{tabular}{ccc}
\hline Day & $\begin{array}{c}\mathrm{A} \\
\left(10^{-6} \mathrm{~s}^{-1}\right)\end{array}$ & $\begin{array}{c}\mathrm{K} \\
\left(10^{-12} \mathrm{~cm}^{3} \mathrm{~s}^{-1}\right)\end{array}$ \\
\hline 78 & 0.8 & 0.8 \\
79 & 1.0 & 0.5 \\
80 & 6.0 & 1.4 \\
82 & 0.9 & 0.4 \\
84 & 0.5 & 0.2 \\
85 & 3.0 & 0.7 \\
87 & 0.5 & 0.2 \\
88 & 2.0 & 0.6 \\
90 & - & - \\
91 & 3.0 & 1.0 \\
92 & 3.0 & 1.0 \\
93 & - & - \\
94 & 1.5 & 0.4 \\
96 & 0.4 & 0.2 \\
97 & 1.0 & 0.3 \\
98 & 0.8 & 0.3 \\
\hline Mean & 1.7 & 0.6 \\
Median & 1.0 & 0.5 \\
Min & 0.4 & 0.2 \\
Max & 6.0 & 1.4 \\
\hline & &
\end{tabular}

that the "activation type" nucleation works better than the "kinetic type" nucleation, although the difference between these two is not very large. Figure 6 shows an example of a day (day 91) when the kinetic nucleation theory seems to work slightly better.

The same kind of visual fitting of the parameters $A$ and $K$, as presented in Figs. 5 and 6 , was made for all 15 event days. The resulting values of $A$ and $K$ are summarized in Table 2. Although the nucleation rates vary quite much from day to day, the coefficients $A$ and $K$ lie approximately within a range of a factor of ten. For the activation coefficient we got values between $0.4 \times 10^{-6}$ and $6.0 \times 10^{-6} \mathrm{~s}^{-1}$ with a mean of $1.7 \times 10^{-6} \mathrm{~s}^{-1}$ and median of $1.0 \times 10^{-6} \mathrm{~s}^{-1}$. The kinetic coefficient had even smaller variability with a minimum value of $0.2 \times 10^{-12} \mathrm{~cm}^{3} \mathrm{~s}^{-1}$, maximum of $1.4 \times 10^{-12} \mathrm{~cm}^{3} \mathrm{~s}^{-1}$, mean of $0.6 \times 10^{-12} \mathrm{~cm}^{3} \mathrm{~s}^{-1}$ and median of $0.5 \times 10^{-12} \mathrm{~cm}^{3} \mathrm{~s}^{-1}$. For comparison, a kinetic coefficient for collisions of two $\mathrm{H}_{2} \mathrm{SO}_{4}$ molecules is about $3 \times 10^{-10} \mathrm{~cm}^{3} \mathrm{~s}^{-1}$ assuming perfect sticking and energy transfer. On the other hand, typical (in upper range) chemical reaction rate coefficients in the gas phase are of the order of $10^{-14}-10^{-12} \mathrm{~cm}^{3} \mathrm{~s}^{-1}$. This means actually that both coefficients - activation and kinetic - are of the same order as chemical reaction rate coefficients in the gas phase assuming that the concentrations of vapours participating in activation are around $10^{6}-10^{8} \mathrm{~cm}^{-3}$.

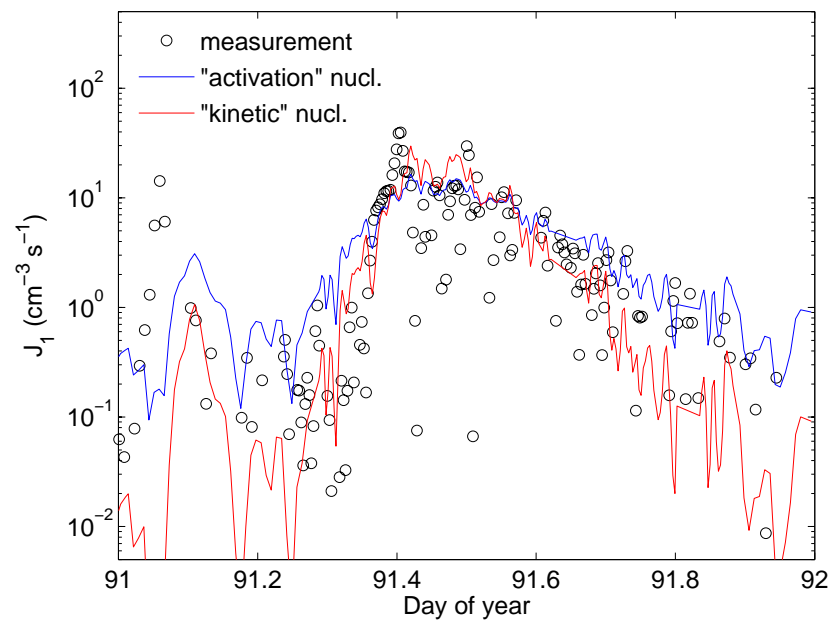

Fig. 6. Nucleation rate on day 91 (1 April 2003) estimated from the particle measurements and calculated from the sulphuric acid concentration using two hypothetic nucleation mechanisms: "activation type" and "kinetic type" nucleation.

For most days it was hard to say reliably whether the "activation type" or "kinetic type" nucleation was better as was done when examining the correlation of $N_{3-6}$ and $\left[\mathrm{H}_{2} \mathrm{SO}_{4}\right]$. Therefore we determined both coefficients $A$ and $K$ for all days, and at this stage make no conclusion on a specific nucleation mechanism on a specific day. An overall picture about the relation is seen from Fig. 7, in which the logarithm of $J_{1}$ estimated from particle measurements is plotted against the logarithm of $\left[\mathrm{H}_{2} \mathrm{SO}_{4}\right]$ for the whole campaign data. Activation type dependence between $J_{1}$ and $\left[\mathrm{H}_{2} \mathrm{SO}_{4}\right]$ should appear in the plot as a line with slope 1 and kinetic type dependence as a line with slope 2. However, as was the case with $\mathrm{N}_{3-6}$ and $\left[\mathrm{H}_{2} \mathrm{SO}_{4}\right]$, the points from different days are mixed and we can only say that in the relationship $J_{1} \sim\left[\mathrm{H}_{2} \mathrm{SO}_{4}\right]^{x}$ the exponent is something between 1 and 2 . On average, the data points to activation type nucleation: a least squares fit to the whole data gives 1.16 for the exponent. The corresponding plot for $J_{3}$ and sulphuric acid (delayed by $\Delta t$ ) is presented in Fig. 8, and similarly $J_{3}$ correlates with $\left[\mathrm{H}_{2} \mathrm{SO}_{4}\right]^{x}$ with exponent $x$ between 1 and 2 .

It should be noted, that even though the relation between $N_{3-6}$ and sulphuric acid was on day $85 N_{3-6} \sim\left[\mathrm{H}_{2} \mathrm{SO}_{4}\right]^{2}$, i.e. with exponent 2 , for nucleation the activation formula (Eq. 5) with direct correlation $J_{1} \sim\left[\mathrm{H}_{2} \mathrm{SO}_{4}\right]$ appears to fit better (see Figs. 2a and 5). Thus the exponents of the correlation $N_{3-6} \sim\left[\mathrm{H}_{2} \mathrm{SO}_{4}\right]^{x}$ listed in Table 1 should not be interpreted as exponents of the nucleation formula. There are several possible reasons for the change in exponent from 1 to 2 when going from correlation $J_{1} \sim\left[\mathrm{H}_{2} \mathrm{SO}_{4}\right]^{x}$ to $N_{3-6} \sim\left[\mathrm{H}_{2} \mathrm{SO}_{4}\right]^{x}$. If sulphuric acid makes the main part of the growth from 1 to $3 \mathrm{~nm}$, it may cause another $\left[\mathrm{H}_{2} \mathrm{SO}_{4}\right]$-dependence to $N_{3-6}$ in addition to the linear dependence in nucleation. Also some organic vapours formed in oxidation reactions with 


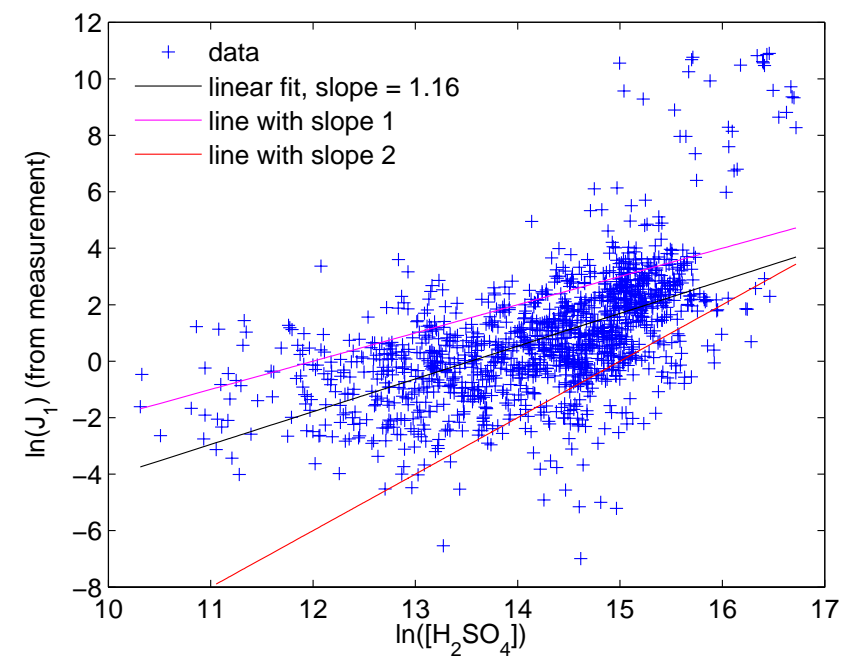

Fig. 7. Logarithm of the nucleation rate $J_{1}$ estimated from particle measurements versus logarithm of the sulphuric acid concentration.

$\mathrm{OH}$ radical can have approximately the same pattern than sulphuric acid, which itself is formed through a reaction with $\mathrm{OH}$, and thereby they may cause an apparent correlation of $N_{3-6}$ with $\left[\mathrm{H}_{2} \mathrm{SO}_{4}\right]^{2}$. Similar apparent relation with $\left[\mathrm{H}_{2} \mathrm{SO}_{4}\right]$ may be caused also by condensation sink, which often decreases in the morning due to dilution of background aerosol when boundary layer develops, and can have a pattern similar to inverse of $[\mathrm{OH}]$.

During the QUEST 2 campaign there were three days (days 81,89 and 95) when no new particle formation was observed. On day 95 sulphuric acid measurements were made, so we can test how large particle formation rates would be expected according to the "activation type" and "kinetic type" nucleation pathways. For the growth rate $G R_{1-3}$ and coefficients $A$ and $K$, median values from the campaign were used. The resulting nucleation rate $\left(J_{1}\right)$ was very low, always smaller than $1 \mathrm{~cm}^{-3} \mathrm{~s}^{-1}$. The formation rate of $3 \mathrm{~nm}$ particles $\left(J_{3}\right)$ was naturally even smaller, always below $0.1 \mathrm{~cm}^{-3} \mathrm{~s}^{-1}$. These formation rates are too small to cause a new particle formation event. Thus also data from this non-event day fits in the framework of "activation type" or "kinetic type" nucleation with coefficients $A$ and $K$ estimated from fittings to data on particle formation days.

3.3 Correlations of the growth rate $G R_{1-3}$ and nucleation coefficients $A$ and $K$ with other quantities

In order to get more information on the particle growth mechanism from 1 to $3 \mathrm{~nm}$ as well as on the nucleation mechanism behind used formulas for nucleation rate (Eqs. 5 and 6), we searched for correlations of the growth rate $\left(G R_{1-3}\right)$ and nucleation coefficients ( $A$ and $K$ ) with several other quantities. Our aim was to find out whether there are quantities that could explain the variation of $G R_{1-3}, A$ and $K$ from

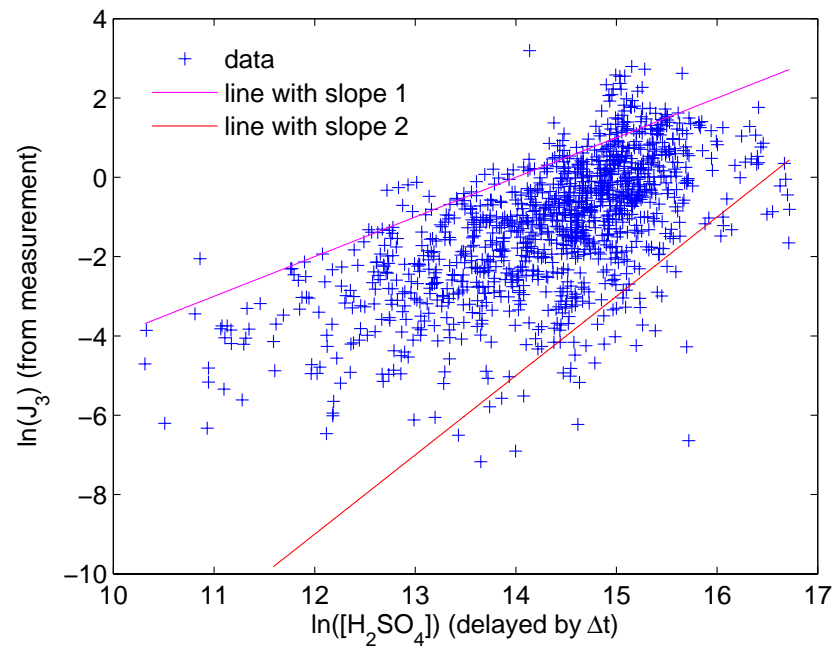

Fig. 8. Logarithm of the formation rate $J_{3}$ estimated from particle measurements versus logarithm of the sulphuric acid concentration. Sulphuric acid concentration has been delayed by $\Delta t$, i.e. the value $J_{3}(t)$ has been associated with the value $\left[\mathrm{H}_{2} \mathrm{SO}_{4}\right](t-\Delta t)$.

day to day. The daytime values, averaged over the period 09:00 a.m.-03:00 p.m., of the following measured quantities were considered: temperature, relative humidity, condensation sink, and the concentrations of sulphuric acid, monoterpenes and ammonia. In addition, correlations with the quantities $[\mathrm{OH}] \times[$ terp $] / \mathrm{CS}$ and $\left[\mathrm{O}_{3}\right] \times[$ terp $] / \mathrm{CS}$, representing the proxies for condensable organic vapours, were investigated.

As already shown in Fig. 3, $G R_{1-3}$ correlated nicely with sulphuric acid concentration. It was the only significant correlation found for $G R_{1-3}$ (correlation coefficient 0.8 ). The correlation coefficients for the nucleation coefficients $A$ and $K$ are presented in Table 3. Temperature, sulphuric acid and ammonia had no significant correlation with the coefficients $A$ and $K$, whereas condensation sink, relative humidity and proxies for condensable organic vapours had a negative correlation. More specifically, there was a positive correlation for $A$ and $K$ with the inverses of these quantities, i.e. $1 / \mathrm{CS}, 1 / \mathrm{RH}, \mathrm{CS} /([\mathrm{OH}] \times[\operatorname{terp}])$ and $\mathrm{CS} /\left(\left[\mathrm{O}_{3}\right] \times[\operatorname{terp}]\right)$. This means that when more terpene oxidation products were present, the values of $A$ and $K$ needed for reproducing the observed new particle formation rates were smaller. It further means that both "activation type" and "kinetic type" nucleation processes seem to depend on the concentration of oxidation products of terpenes, being more effective at higher concentrations. The coefficient for "kinetic type" nucleation, $K$, had a stronger correlation with $\mathrm{CS} /([\mathrm{OH}] \times[$ terp $])$ and $\mathrm{CS} /\left(\left[\mathrm{O}_{3}\right] \times[\right.$ terp $\left.]\right)$ than did the coefficient for "activation type" nucleation, $A$.

We tested also correlations with some products of the quantities mentioned above. Interestingly, $A$ and $K$ seemed to correlate with $\left[\mathrm{H}_{2} \mathrm{SO}_{4}\right] \times\left[\mathrm{NH}_{3}\right]$ even if there was no significant correlation with sulphuric acid or ammonia alone. 
The correlation coefficients of $A$ with $\left[\mathrm{H}_{2} \mathrm{SO}_{4}\right]$ and $\left[\mathrm{NH}_{3}\right]$ were 0.42 and 0.25 , respectively, and those of $K$ with $\left[\mathrm{H}_{2} \mathrm{SO}_{4}\right]$ and $\left[\mathrm{NH}_{3}\right]$ were 0.17 and 0.3 , respectively. However, correlation coefficients with $\left[\mathrm{H}_{2} \mathrm{SO}_{4}\right] \times\left[\mathrm{NH}_{3}\right]$ were considerably greater: 0.66 for $A$ and 0.62 for $K$. This correlation suggests that both sulphuric acid and ammonia are important in new particle formation. The higher the sulphuric acid and ammonia concentrations, the larger are the nucleation coefficients. This means that in case of activation type nucleation, a larger fraction of sulphuric acid molecules gets activated to $3 \mathrm{~nm}$ size, and in case of kinetic type nucleation, a larger fraction of collisions of two molecules containing sulphuric acid leads to formation of permanent clusters.

Although the correlations found are very promising, it should be kept in mind that the used dataset was rather small (10-14 days). This is due to the fact that on some analysed days a fraction of data, such as ammonia concentration, was missing. Therefore the correlations found are mainly suggestive.

\section{Conclusions}

In this study, the close correlation between number concentration of freshly nucleated particles $(3-6 \mathrm{~nm})$ and sulphuric acid has been investigated in detail to analyze the formation and growth mechanism of atmospheric aerosol particles. The analysis was based on data on 15 new particle formation days observed during QUEST 2 campaign in spring 2003 in Hyytialä (Finland). During new particle formation, the concentration of 3-6 nm particles was found to have a power-law dependence on the sulphuric acid concentration, with an exponent value 1 or 2 . Using time shift analysis based on this correlation, the growth rate from $1 \mathrm{~nm}$ to $3 \mathrm{~nm}$ has been determined. The mean value was $1.2 \mathrm{~nm} / \mathrm{h}$ and a large fraction of it, on average about $50 \%$, can be explained by the condensation of sulphuric acid.

Formation rates of $3 \mathrm{~nm}$ and $1 \mathrm{~nm}$ particles estimated from particle measurements were correlated with sulphuric acid concentration to the power from 1 to 2 , showing that there are possibly couple of varying nucleation mechanisms working during the analyzed period. Recently we have presented an activation theory to describe the linear dependence between sulphuric acid concentration and atmospheric nucleation rate (Kulmala et al., 2006). Here we tested two nucleation mechanisms corresponding to the two dependences: "activation type" nucleation with linear dependence and "kinetic type" nucleation with square dependence on sulphuric acid. According to our analysis, both mechanisms seem to be good candidates for atmospheric nucleation. From fittings to particle measurement data empirical nucleation coefficients were determined. The mean values of the activation and kinetic coefficients were $1.7 \times 10^{-6} \mathrm{~s}^{-1}$ and $0.6 \times 10^{-12} \mathrm{~cm}^{3} \mathrm{~s}^{-1}$, respectively, being of the same order of magnitude as chemical
Table 3. Correlation coefficients for activation and kinetic coefficients $A$ and $K$ with daytime averages (09:00 a.m.-03:00 p.m.) of several quantities during QUEST 2 campaign. Correlation coefficients greater than 0.5 are marked as bold.

\begin{tabular}{lccc}
\hline & $\mathrm{A}$ & $\mathrm{K}$ & $\begin{array}{c}\text { Number of } \\
\text { data points }\end{array}$ \\
\hline $\mathrm{T}$ & -0.25 & -0.29 & 14 \\
$R H$ & $-\mathbf{0 . 5 2}$ & $-\mathbf{0 . 5 5}$ & 14 \\
{$\left[\mathrm{H}_{2} \mathrm{SO}_{4}\right]$} & 0.42 & 0.17 & 14 \\
{$\left[\mathrm{NH}_{3}\right]$} & 0.25 & 0.30 & 10 \\
{$[$ terp $]$} & 0.07 & -0.32 & 12 \\
{$[$ terp $] \times[\mathrm{OH}] / \mathrm{CS}$} & $-\mathbf{0 . 5 2}$ & $-\mathbf{0 . 6 2}$ & 12 \\
{$[$ terp $] \times\left[\mathrm{O}_{3}\right] / \mathrm{CS}$} & -0.43 & $-\mathbf{0 . 5 5}$ & 12 \\
$\mathrm{CS}$ & $\mathbf{0 . 5 1}$ & 0.42 & 14 \\
& & & \\
$R H^{-1}$ & $\mathbf{0 . 5 9}$ & $\mathbf{0 . 6 1}$ & 14 \\
$([\text { terp }] \times[\mathrm{OH}] / \mathrm{CS})^{-1}$ & $\mathbf{0 . 6 7}$ & $\mathbf{0 . 8 0}$ & 12 \\
$\left([\text { terp }] \times\left[\mathrm{O}_{3}\right] / \mathrm{CS}\right)^{-1}$ & $\mathbf{0 . 5 4}$ & $\mathbf{0 . 7 2}$ & 12 \\
{$\left[\mathrm{H}_{2} \mathrm{SO} \mathrm{S}_{4}\right] \times\left[\mathrm{NH}_{3}\right]$} & $\mathbf{0 . 6 6}$ & $\mathbf{0 . 6 2}$ & 10 \\
& & & \\
$\mathrm{GR}_{1-3}$ & 0.09 & 0.007 & 13 \\
\hline
\end{tabular}

reaction rate coefficients in the gas phase with vapour concentrations around $10^{6}-10^{8} \mathrm{~cm}^{-3}$.

Due to big scatter in $J_{3}$ and $J_{1}$ data, we didn't specify exactly whether the particle formation occurs according to the activation or kinetic mechanism on a particular day, but determined both coefficients $A$ and $K$ for all days. We want to emphasize that the exponents of the correlation for the number concentration $\left(N_{3-6} \sim\left[\mathrm{H}_{2} \mathrm{SO}_{4}\right]^{x}\right)$ should not be interpreted as the exponents of the nucleation formula. For various reasons the exponent of the correlation may change when going form $J_{1}$ to $J_{3}$ and $N_{3-6}$. More data analysis is needed to make conclusions on which nucleation mechanism will dominate in which conditions.

When analyzing the dependence of activation and kinetic coefficients on other measured data, a correlation with $\left[\mathrm{H}_{2} \mathrm{SO}_{4}\right] \times\left[\mathrm{NH}_{3}\right]$ was seen, even though there was no correlation with $\left[\mathrm{H}_{2} \mathrm{SO}_{4}\right]$ or $\left[\mathrm{NH}_{3}\right]$ alone. Also the anticorrelation with the concentration of oxidation products of terpenes was observed, indicating that the higher their concentrations, the smaller the activation and kinetic coefficients are. Although at present only indicative, this gives a clear hint that all three gaseous precursors - sulphuric acid, ammonia and terpene oxidation products - are important in formation and growth of atmospheric aerosol particles.

Recently there has been some experimental development to detect neutral clusters below $3 \mathrm{~nm}$ in atmospheric conditions (see Kulmala et al., 2005a). However, $3 \mathrm{~nm}$ is still the lower limit in conventional atmospheric aerosol particle measurements, and the current estimates on the magnitude of regional and global secondary aerosol formation rely mainly 
on modelling and are subject to large uncertainties. There are uncertainties in identifying both the detailed nucleation mechanisms and the nucleation rates, and the formation rate of $3 \mathrm{~nm}$ particles depends strongly on growth rate from 1 to $3 \mathrm{~nm}$. By analyzing the relationship between sulphuric acid and freshly formed particles we can get indirectly information about the early stages of particle formation. For this type of data analysis, it is crucial to measure particles and sulphuric acid simultaneously. To find out how broadly these types of correlations are valid, it would be essential to analyze data from different environments. We will continue the study also by aerosol dynamics modelling to deeper understand the physical phenomena behind the close correlation between the concentrations of sulphuric acid and freshly nucleated particles.

Edited by: K. Hämeri

\section{References}

Bernd, T., Böge, O., Stratmann, F., Heintzenberg, J., and Kulmala, M.: Rapid formation of new sulfuric acid particles at nearatmospheric conditions, Science, 307(5710), 698-700, 2005.

Birmili, W. and Wiedensohler, A.: The influence of meteorological parameters on ultrafine particle production at a continental site, J. Aerosol Sci., 29, S1015-1016, 1998.

Birmili, W., Berresheim, H., Plass-Dülmer, C., Elste, T., Gilge, S., Wiedensohler, A., and Uhrner, U.: The Hohenpeissenberg aerosol formation experiment (HAFEX): a long-term study including size-resolved aerosol, $\mathrm{H}_{2} \mathrm{SO}_{4}, \mathrm{OH}$, and monoterpenes measurements, Atmos. Chem. Phys., 3, 361-376, 2003, http://www.atmos-chem-phys.net/3/361/2003/.

Boy, M., Kulmala, M., Ruuskanen, T. M., Pihlatie, M., Reissell, A., Aalto, P. P., Keronen, P., Dal Maso, M., Hellen, H., Hakola, H., Jansson, R., Hanke, M., and Arnold, F.: Sulphuric acid closure and contribution to nucleation mode particle growth, Atmos. Chem. Phys., 5, 863-878, 2005, http://www.atmos-chem-phys.net/5/863/2005/.

Cabada, J. C., Khlystov, A., Wittig, A. E., Pilinis, C., and Pandis, S. N.: Light scattering by fine particles during the Pittsburgh Air Quality Study: Measurements and modelling, J. Geophys. Res., 109, D16S03, doi:10.1029/2003JD004155, 2004.

Dal Maso, M., Kulmala, M., Riipinen, I., Wagner, R., Hussein, T., Aalto, P. P., and Lehtinen, K. E. J.: Formation and growth of fresh atmospheric aerosols: eight years of aerosol size distribution data from SMEAR II, Hyytiälä, Finland, Boreal Environ. Res., 10, 323-336, 2005.

Donaldson, K., Li, X. Y., and MacNee, W.: Ultra-fine (nanometre) particle mediated lung injury, J. Aerosol. Sci., 29, 553-560, 1998.

Dunn, M. J., Jimenez, J.-L., Baumgartner, D., Castro, T., McMurry, P. H., and Smith, J. N.: Measurements of Mexico City nanoparticle size distributions: Observations of new particle formation and growth, Geophys. Res. Lett., 31, L10102, doi:10.1029/2004GL019483, 2004.

Fiedler, V., Dal Maso, M., Boy, M., Aufmhoff, H., Hoffmann, J., Schuch, T., Birmili, W., Hanke, M., Uecker, J., Arnold, F., and
Kulmala, M.: The contribution of sulphuric acid to atmospheric particle formation and growth: a comparison between boundary layers in Northern and Central Europe, Atmos. Chem. Phys., 5, 1773-1785, 2005, http://www.atmos-chem-phys.net/5/1773/2005/.

Hanke, M., Uecker, J., Reiner, T., and Arnold, F.: Atmospheric peroxy radicals: ROXMAS, a new mass-spectrometric methodology for speciated measurements of $\mathrm{HO} 2$ and Sigma $\mathrm{RO} 2$ and first results, Int. J. Mass Spectr., 213(2-3), 91-99, 2002.

Hari, P. and Kulmala, M.: Station for Measuring EcosystemAtmosphere Relations (SMEAR II), Boreal Environ. Res., 10, 315-322, 2005.

Janson, R., Rosman, K., Karlsson, A., and Hansson, H.-C.: Biogenic emissions and gaseous precursors to forest aerosols, Tellus 53B, 423-440, 2001.

Kerminen, V.-M. and Kulmala, M.: Analytical formulae connecting the "real" and the "apparent" nucleation rate and the nuclei number concentration for atmospheric nucleation events, J. Aerosol Sci., 33, 609-622, 2002.

Korhonen, H., Lehtinen, K. E. J., and Kulmala, M.: Multicomponent aerosol dynamics model UHMA: model development and validation, Atmos. Chem. Phys., 4, 757-771, 2004, http://www.atmos-chem-phys.net/4/757/2004/.

Korhonen, P., Kulmala, M., Laaksonen, A., Viisanen, Y., McGraw, R., and Seinfeld, J. H.: Ternary nucleation of $\mathrm{H}_{2} \mathrm{SO}_{4}, \mathrm{NH}_{3}$ and $\mathrm{H}_{2} \mathrm{O}$ in the atmosphere, J. Geophys. Res., 104, 26349-26353, 1999.

Kulmala, M., Toivonen, A., Mäkelä, J. M., and Laaksonen, A.: Analysis of the growth of nucleation mode particles observed in Boreal forest, Tellus, 50B, 449-462, 1998.

Kulmala, M., Hämeri, K., Aalto, P. P., Mäkelä, J. M., Pirjola, L., Nilsson, E. D., Buzorius, G., Rannik, Ü, Dal Maso, M., Seidl, W., Hoffmann, T., Janson, R., Hansson, H.-C., Viisanen, Y., Laaksonen, A., and O'Dowd, C. D.: Overview of the international project on Biogenic aerosol formation in the boreal forest (BIOFOR), Tellus 53B, 324-343, 2001a.

Kulmala, M., Dal Maso, M., Mäkelä, J. M., Pirjola, L., Väkevä, M., Aalto, P,. Miikkulainen, P., Hämeri, K., and O’Dowd, C. D.: On the formation, growth and composition of nucleation mode particles, Tellus, 53B, 479-490, 2001b.

Kulmala, M.: How Particles Nucleate and Grow, Science, 302, 1000-1001, 2003.

Kulmala, M., Vehkamäki, H., Petäjä, T., Dal Maso, M., Lauri, A., Kerminen, V.-M., Birmili, W., and McMurry, P. H.: Formation and growth rates of ultrafine atmospheric particles: A review of observations, J. Aerosol Sci., 35, 143-176, 2004a.

Kulmala, M., Laakso, L., Lehtinen, K. E. J., Riipinen, I., Dal Maso, M., Anttila, T., Kerminen, V.-M., Horrak, U., Vana, M., and Tammet, H.: Initial steps of aerosol growth, Atmos. Chem. Phys., 4, 2553-2560, 2004b.

Kulmala, M., Lehtinen, K. E. J., Laakso, L., Mordas, G., and Hämeri, K.: On the existence of neutral atmospheric clusters, Boreal Environ. Res., 10, 79-87, 2005a.

Kulmala, M., Lehtinen, K. E. J., and Laaksonen, A.: Cluster activation theory as an explanation of the linear dependence between formation rate of $3 \mathrm{~nm}$ particles and sulphuric acid concentration, Atmos. Chem. Phys., 6, 787-793, 2006, http://www.atmos-chem-phys.net/6/787/2006/.

Laakso, L., Anttila, T., Lehtinen, K. E. J., Aalto, P. P., Kulmala, 
M., Hõrrak, U., Paatero, J., Hanke, M., and Arnold, F.: Kinetic nucleation and ions in boreal particle formation events, Atmos. Chem. Phys., 4, 2353-2366, 2004a.

Laakso, L., Petäjä, T., Lehtinen, K. E. J., Kulmala, M., Paatero, J., Hõrrak, U., Tammet, H., and Joutsensaari, J.: Ion production rate in a boreal forest based on ion, particle and radiation measurements, Atmos. Chem. Phys., 4, 1933-1943, $2004 \mathrm{~b}$.

Laaksonen, A., Hamed, A., Joutsensaari, J., Hiltunen, L., Cavalli, F., Junkermann, W., Asmi, A., Fuzzi, S., and Faccini, M. C.: Cloud condensation nucleus production from nucleation events at a highly polluted region, Geophys. Res. Lett., 32, L06812, doi:10.1029/2004GL022092, 2005.

Lehtinen, K. E. J. and Kulmala, M.: A model for particle formation and growth in the atmosphere with molecular resolution in size, Atmos. Chem. Phys., 3, 251-257, 2003, http://www.atmos-chem-phys.net/3/251/2003/.

Lohmann, U. and Feichter, J.: Global indirect aerosol effects: a review, Atmos. Chem. Phys., 5, 715-737, 2005, http://www.atmos-chem-phys.net/5/715/2005/.

Lushnikov, A. A. and Kulmala, M.: Dimers in nucleating vapors, Phys. Rev. E, 58, 3157-3167, 1998.

McMurry, P. H. and Friedlander, S. K.: New particle formation in the presence of an aerosol, Atmos. Environ., 13, 1635-1651, 1979.

Mäkelä, J. M., Aalto, P., Jokinen, V., Pohja, T., Nissinen, A., Palmroth, S., Markkanen, T., Seitsonen, K., Lihavainen, H., and Kulmala, M.: Observations of ultrafine aerosol particle formation and growth in boreal forest, Geophys. Res. Lett., 24, 1219-1222, 1997.

Mönkkönen, P., Koponen, I. K., Lehtinen, K. E. J., Hämeri, K., Uma, R., and Kulmala, M.: Measurements in a highly polluted Asian mega city: Observations of aerosol aerosol number size distributions, modal parameters and nucleation events, Atmos. Chem. Phys., 5, 57-66, 2005,

http://www.atmos-chem-phys.net/5/57/2005/.

O'Dowd, C., McFiggans, G., Creasey, D. J., Pirjola, L., Hoell, C., Smith, M. H., Allan, B. J., Plane, J. M. C., Heard, D. E., Lee, J. D., Pilling, M. J., and Kulmala M.: On the photochemical production of new particles in the coastal boundary layer, Geophys. Res. Lett., 26, 1707-1710, 1999.

Ramanathan, V., Crutzen, P. J., Kiehl, J. T., and Rosenfeld, D.: Aerosol, climate, and the hydrological cycle, Science, 294, 2119-2124, 2001.

Sekiguchi, M., Nakajima, T., Suzuki, K., Kawamoto, K., Higurashi, A., Rosenfeld, D., Sano, I., and Mukai, S.: A study of the direct and indirect effects of aerosols using global satellite data sets of aerosol and cloud parameters, J. Geophys. Res., 108(D22), 4699, doi:10.1029/2002JD003359, 2003.

Smith, J. N., Moore, K. F., Eisele, F. L., Voisin D., Ghimire, A. K., Sakurai H., and McMurry, P. H.: Chemical composition of atmospheric nanoparticles during nucleation events in Atlanta, J. Geophys. Res., 110, D22S03, doi:10.1029/2005JD005912, 2005.
Stanier, C. O., Khlystov, A. Y., and Pandis, S. N.: Nucleation events during the Pittsburg Air Quality Study: Description and relation to key meteorological, gas phase and aerosol parameters, Aerosol Sci. Technol., 38(S1), 253-264, 2004.

Stolzenburg, M. R., McMurry, P. H., Sakurai, H., Smith, J. N., Mauldin III, R. L., Eisele, F. L., and Clement, C. F.: Growth rates of freshly nucleated particles in Atlanta, J. Geophys. Res., 110, D22S05, doi:10.1029/2005JD005935, 2005.

Stieb, D. M., Judek, S., and Burnett, R.T.: Meta-analysis of timeseries studies of air pollution and mortality: Effects of gases and particles and their influence of cause of death, age and season, J. Air \& Manage. Assoc., 52, 470-484, 2002.

Vana, M., Kulmala, M., Dal Maso, M., Hõrrak, U., and Tamm, E.: Comparative study of nucleation mode aerosol particles and intermediate air ions formation events at three sites, J. Geophys. Res., 109, D17201, 2004.

Vehkamäki, H., Dal Maso, M., Hussein, T., Flanagan, R., Hyvärinen, A., Lauros, J., Merikanto, J., Mönkkönen, P., Pihlatie, M., Salminen, K., Sogacheva, L., Thum, T., Ruuskanen, T., Keronen, P., Aalto, P., Hari, P., Lehtinen, K., and Kulmala, M.: Atmospheric particle formation events at Värriö measurement station in Finnish Lapland 1998-2002, Atmos. Chem. Phys., 4, 2015-2023, 2004, http://www.atmos-chem-phys.net/4/2015/2004/.

Väkevä, M., Hämeri, K., Puhakka, T., Nilsson, E. D., Hohti, H., and Mäkelä, J. M.: Effects of meteorological processes on aerosol particle size distribution in an urban background area, J. Geophys. Res., 105, 9807-9821, 2000.

Weber, R. J., McMurry, P. H., Eisele, F. L., and Tanner, D. J.: Measurement of expected nucleation precursor species and 3-500 nm diameter particles at Mauna Loa Observatory, Hawaii, J. Atmos. Sci., 52, 2242-2257, 1995.

Weber, R. J., Marti, J. J., McMurry, P. H., Eisele, F. L., Tanner, D. J., and Jefferson, A.: Measurements of new particle formation and ultrafine particle growth rates at a clean continental site, J. Geophys. Res., 102, 4375-4385, 1997.

Wehner, B., Wiedensohler, A., Tuch, T. M., Wu, Z. J., Hu, M., Slanina, J., and Kiang, C. S.: Variability of the aerosol number size distribution in Beijing, China: New particle formation, dust storms, and high continental background, Geophys. Res. Lett., 31, L22108, doi:10.1029/2004GL021596, 2004.

Zhang, Q., Stanier, C. O., Canagaratna, M. R., Jayne, J. T., Worsnop, D. R., Pandis, S. N., and Jimenez, J. L.: Insights into the chemistry of new particle formation and growth events in Pittsburg based on aerosol mass spectrometry, Environ. Sci. Technol., 38, 4797-4809, 2004. 